\title{
The Clementine Bistatic Radar Experiment
}

S. Nozette, ${ }^{*}$ C. L. Lichtenberg, P. Spudis, R. Bonner, W. Ort, E. Malaret, M. Robinson, and E. M. Shoemaker 


\section{The Clementine Bistatic Radar Experiment}

\section{S. Nozette, ${ }^{\star}$ C. L. Lichtenberg, P. Spudis, R. Bonner, W. Ort, E. Malaret, M. Robinson, E. M. Shoemaker}

During the Clementine 1 mission, a bistatic radar experiment measured the magnitude and polarization of the radar echo versus bistatic angle, $\beta$, for selected lunar areas. Observations of the lunar south pole yield a same-sense polarization enhancement around $\beta=0$. Analysis shows that the observed enhancement is localized to the permanently shadowed regions of the lunar south pole. Radar observations of periodically solar-illuminated lunar surfaces, including the north pole, yielded no such enhancement. A probable explanation for these differences is the presence of low-loss volume scatterers, such as water ice, in the permanently shadowed region at the south pole.

The pussibility of ice on the mon was suggested in 1961 (1). Volatiles degassed from the primitive moon or deposited on the lunar surface by cometary and asteroidal impacts might migrate to and collect in permanently shadowed cold traps near the lunar poles, where they could be stahle over geologic time $(1-5)$. Because these cold traps receive no direct solar illumination, and emit little radiation, they are difficult

S. Nozette, U.S. Air Force Phillips Laboratory, Space Experiments Directorate, 711 North Fayette Street, Alexandria. VA 22314, USA

C. L. Lichtenberg, Naval Research Laboratory, Washing ton, DC 20375, USA.

P. D. Spudis, Lunar and Planetary institute, Houston. TX 77058, USA

R. Bonner and W. Ort, Protasis Incorporated, Alexandria.

VA 22314. USA

E. Malaret, Applied Conerent Technology. Herndon, VA 22070 , USA.

M. Robinson and E. M. Shoemaker, U.S. Geological Sur vey. Flagstaff, AZ 86001. USA

"To whom correspondence should be addressed. to observe from the Earth. Radar can identify deposits of frozen volatiles hecause, under certain conditions, they produce a unique radar signature (6). However, such radar ubservations may not be conclusive depending on the quantity of volatiles present, the nature of the surface, and the sensitivity of the measurements. Frozen volatiles have much lower transmission loss than silicate rocks, producing a higher average radar reflectivity than silicate rocks. Total internal reflection also preserves the transmitted circular polarization sense in the scattered signal. An opposition surge or coherent hackscalter opposition effect (CBOE) (7-12) may also he ohserved as the phase, or histatic angle $\beta$ (Fig. 1), approaches 0 . The CBOE requires scattering centers (cracks or inhomogeneities) imbedded in a low loss matrix such as ice (7-9). The preservation of the sense of pollarization for CBOE has been observed in the laheratery using latser illumination of a particle suspension $(13,14)$. A high ration of same sense to opposite sense pollarization and high reflectivity has been detected hy radar observations of the Galilean satellites of Jupiter $(15,16,17)$, the residual south pular ice ciap of Mars (18), purtions of the Greenland ice sheet $(19,20)$, and the permanently shadowed polar craters of Mercury (21-23). These results are generally attributed to total internal reflection and/or (CBC)E produced by low lows frozen volatiles (6), although other mechanisms have heen proposed (24). High-resolution ground-hased synthetic aperture (monostatic) radar observations, from Arecibo, of the lunar south pole revealed some small anomalous samesense polarization bright patches that are permanently shadowed (25). Brightening and enhancement of sime sense polarization can be caused by doutle bounce reflections from large hlocks or surface roughness. The presence of $(\mathrm{BO}) \mathrm{E}$ could distinguish brightening and polarization reversal produced by a low loss target from orher scartering mechanisms. Bistatic radar measurements, using a spicecrift in orbit acting als the transmitter, can he used an a tent for CBOE $(13,14,20)$ by measuring the echo magnitude and polarization sense as a function of $\beta$.

The Clementine 1 mission (26) provided data on the environment and geology of the polar regions of the moen $(27,28)$. In the northern hemisphere, no large hasin werlaps the polar area. The south pole, however, is locited within the South PoleAitken basin (SPA), an impact crater over $2500 \mathrm{~km}$ in diameter and averaging $12 \mathrm{~km}$ deep near the center of the hasin (29). The pole is ahour $200 \mathrm{~km}$ inside the rim crest of

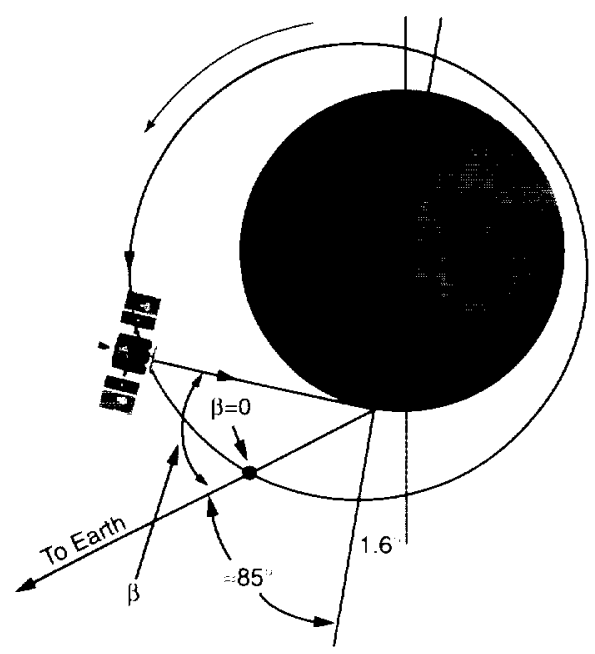

Fig. 1. Orbital geometry of the Clementine bistatic radar experiment. The lunar polar tilt relative to the ecliptic $\left(1.6^{\prime \prime}\right)$, the lunar tilt toward Earth $\left(-5^{\circ}\right)$, and the bistatic angle $\beta$ between spacecraft, lunar surface, and Earth receiver are shown. 
the SIPA. Becolese of it lication inside this topengraphice las, the cleveltion of the senth pole is likely to he several kilumeters bekw the me:in lunar ridius, resulting in zones of perminen shodum $(27,28)$. As the (ilementine liser altimeter dis not eperate for lunar lattitudes greater than $70^{\circ}$, there is no altimetry datia for the polar regioms. However, multiring bisins tend to preserve concontric symmery (30), thus the lunar south pole is estimated to lic about 5 to $8 \mathrm{~km}$. below the highest point of the basin rim (29). If the ckevation of the SPA rim crest on the near side is ahout $1 \mathrm{~km}$, als sugecsted by the glohal map (31), then the pole would lic at an elevation of athout $-4 \mathrm{fo}-7 \mathrm{~km}$. Study of the illumination conditions near the south pole of the mone during the mision reveal near constint illumination of several points within $30 \mathrm{~km}$ of the pole is well as darkness for other areas. Not all dark

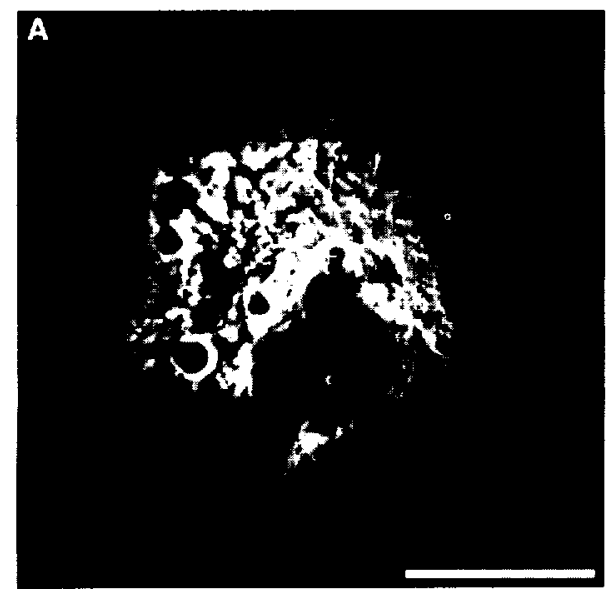

Fig. 2. Composite Clementine orbital images of the poles of the moon, where more than 50 separate images have been summed together over one lunar day. In these views, areas of near permanent illumination are white and areas of near permanent darkness are black. Within $100 \mathrm{~km}$ of each pole. the south pole (B) shows considerable darkness (= cold traps) whereas the immediate surroundings of the north pole (A) show at least an order of magnitude greater illumination, and are therefore warmer. The scale bar is $100 \mathrm{~km}$.

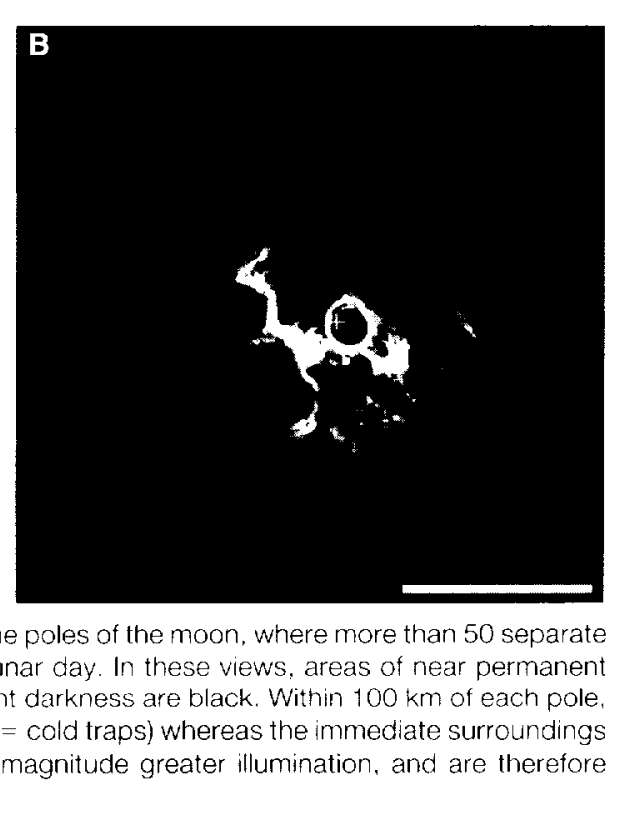

regions oherved by chementine are permatnently dark, as the images were ohtained dering southern winter, near the time when the lemar spin axis whained its maximum tilt awaly from the sun $\left(1.6^{\circ}\right)$. Initial analysis sugegented that up to $30,000 \mathrm{~km}^{2}$ near the south pole was dark during the mission (27). Further analysis of the (lementine images of the south pole taken over a twomonth period thowed that some of this region was illuminated for a small portion $(<10 \%)$ of the lumar month. Images of the north pole raken on alternate orbits $(10$ hour intervals) during the first month and imiges of the south pole taken during the second month were registered and added together to make componite intges showing the extent of illuminated and darkened areas (Fig. 2). These composite imiges show the extent of darkness near the south pole is much greater than that around the north

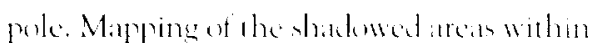
a $2.5^{\circ}$ lat itude $(75 \mathrm{~km})$ radius circle of huth poles reveals at least $6361 \mathrm{~km}$ " of darkne.. around the south pole while only $530 \mathrm{~km}^{2}$ of darkness is moasured around the north pole. A comservatioce analysis suggests an upper limit of $15,500 \mathrm{~km}$ " of serth pole terrain is likely to he in permanent darthness. As the cold trap area at the south polle is more extensive thin at the north pole, it would he expected (2) re retain mote trapped volatiles.

In April 1994, during the times when the Earth passed through the C.lenentine orhital plane, the lumar axial tilt toward the Earth als viewed from the NASA Deep Space Network (I SSN) was relatively large $\left(4.5^{\circ}\right.$ to $\left.5.5^{\circ}\right)$. This fivorable alignment occurred once for cach pole during the month. At these times the spaceoraft, lunat target, and Earth-bised receiver were coplanar with the spacecraft orhital plane, and included the polar $\beta=0$ ondition (Fig. 1). Clementine transmitted an unmedulatedsihand $(2.273$ (illz, $13.19 \mathrm{~cm}$ warclength) right circular polarization (RC.P) sion.l with a net power of about $6 \mathrm{~W}$ through its $1.1 \mathrm{~m}$ high gain antenna (I I(jA), toward a specific lumar tareret. () ne of the 1 )SN $70-m$ antennass served ats a receiver. ( ) 9 and 10 April 1994, histatic redat alservations were made of the south pole region during orhits 234, 235, 236, and 237. () 23 and 24 April 1994, ohservations of the morth pole were conducted on whits 209, 301, and 302. Analytical results for orluits 234, 235, 301, and 302 are presented here. The ather orhits had systematic corom originating in the spacecraft and the ground stations that made the data unusable. Interpretation of the surtace physical preperties involved comparison of the measured echo compenents with scittering molels (32). In the intial analysis, the polarization ration was compired to $\beta$ and lecal surface angle of

Fig. 3. (A) Circular polarization ratio $(\mathrm{RCP} / \mathrm{LCP})$ as a function of $\beta$ for orbit 234 for a 2.5 radius latitude band centered on the lunar south pole and for orbit 235, for a 2.5 radius periodically illuminated band centered at $82.5 \mathrm{~S}$, and for orbits 301 and 302 , orig inating from a $2.5^{\circ}$ radius band centered at the north pole. The area sampled is approximately $45,000 \mathrm{~km}$ ' (orbits 234,301 , and 302) to $170,000 \mathrm{~km}$ (orbit 235). (B) Individual polarization

A

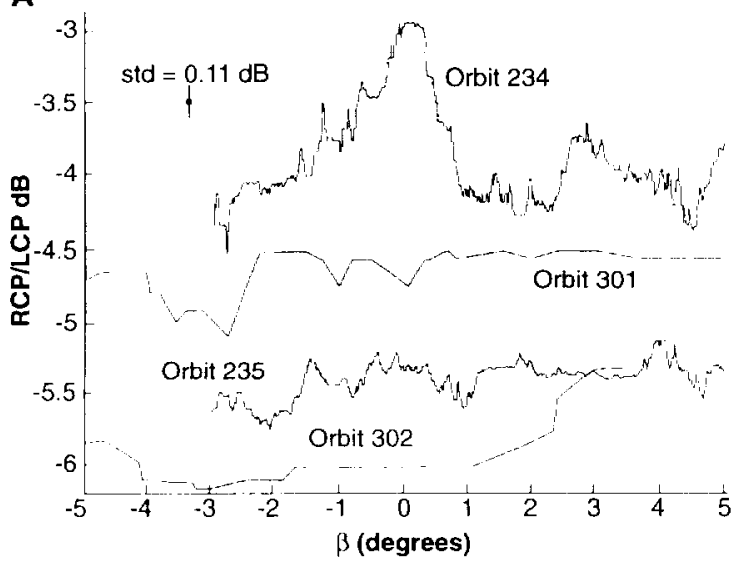

B

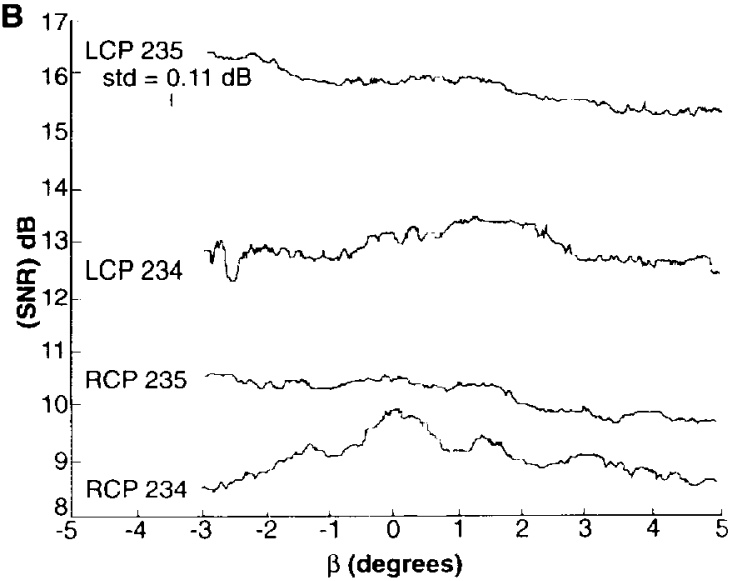

channel (RCP and LCP) echo power response used on a frequency bin-by-bin basis to compute the orbit 234 and 235 polariation ratios. 
incidence (33). The scattering values presented represent regional averages. The normalized radar hackscatter cross section (radar crons section per unit areal) wals estimated from the raddar equation (34) and specific areas illuminated on the lunar surface. Typical values of normalized radier cross section derived from Clementine datis for the near-polar regions, $-80^{\circ}(S)$ to $-82.5^{\circ}$ (S) $\left(84^{\circ}\right.$ angle of incidence, $\beta=$ $\pm 1^{\circ}$ ), are -29 AB LCS (left circular polarizattion) and $-33.5 \mathrm{~dB}$ RC.P, consistent with previous work (25). During orhit 234 the $\beta=0$ track (the locus of $\beta=0$ points) and the center of the HQA beam were cluse (within $0.5^{\circ}$ of each other and the south pole) which provided for good illumination of the entire permanently shadowed wouth pole region at the $\beta=0$ condition. (Orhit 235 hat no $\beta=0$ points near the south pole and is representative of periodically solas itluminated lunar surface. A noticeable peak in RCP/LCP occurs around $\beta=0$ for the orhit $234 \mathrm{D}$ )oppler hins contained within a $2.5^{\circ}$ radius band centered on the lunar south pole (Figs, 3 and 4). Orhit 235 yiedded no discernible enhancement in latitude bands that exclude the south pole region (Fig. 3). The peak in the RCP/LCP ratio observed in orhit 234 , at $\beta=0$, is due to enhanced power received in the RCP channel (Fig. 3) as opposed to a reduction in LCP, as seen at $\beta-2.5$ to $3.0^{\circ}$. No statistically significant enhancement was ohserved in orbit 234 ICC.P (35).

D)uring orhits 301 and 302 the spacecratt was roughly four times closer to the lunat north pole surface at $\beta=0$ than during the south pole observitions. The corresponding antema pattern had a proportionally smaller fourprint, and the incident power density was roughly an order of magnitude greater than for the lunar south pole. More sensitivity is therefore expected in detecting souttering enhancement. The lunar north pole observations showed no statistically significant polarization enhancements at $\beta$ $=0$ (Fig. 3). These abervations were averaged over a latitude hand of $2.5^{\circ}$ radius, centered on the north pole, containing an area comparathle with the orbit 234 south pole observarions. As the spacecraft velocity was greater near the north pole there are fewer $\beta=0$ points in orbits 301 and 302 This produces flatter curves due to the filtering process (Fig 3).

Clementine polar observations were conducted at incidence angles of $82^{\circ}$ to $90^{\circ}$. High incidence angle scattering is difficult to predict and can exhibit unusual hehavior due to shakbwing, diffraction, and multiple scattering effects (36). However no polarization ratio enhancement was ohserved on orhits 301 and 302 , which hat similar high incidence angle geometry and greater sur- face power illumination than orbits 234 and 235. Additionally, orbits 234, 235, 301, and 302 were re-analyzed, independently of $\beta$, to include only target areas at high local incidence angles $\left(82^{\circ}\right.$ to $\left.90^{\circ}\right)$. Only orbit 234 showed an enhanced polarization ratio at high local incidence angles, which independently correxponds to south pole illumination at small $\beta$. All other orbits exhihited hower polarization ratio and no heal angle of incidence dependent RCP/LC.P enhancements. Statistical analysis (37) yields only a small probahility $(<5 \%)$ that the polarization ratio enhancement on orbit 234 is due to random variation in the datit (Table 1), and is probahly not attributable to angle of incidence.

It is not certain whether the enhancement seen in orhit 234 is due to C.BOE or some other scattering effect. The C.BOE peak usually predicted from lossless volume scatrering shoukl be much narrower $\left(<0.1^{\circ}\right)$, and also show a lareer enhancement in RCP and LC,P, than wass ohserved $(7-12,23)$. There are several possible explanations for these ohservations, including the possibility that they are not due to C.BOE from ice deposits. The orbir 234 data have heen averaged over a large area of lunar surface $\left(45,000 \mathrm{~km}^{2}\right)$ of which 14 to $33 \%$ is permanently shadowed (Fig. 4). If the putative ice deposits are small and patchy, the magnitude of the polarization

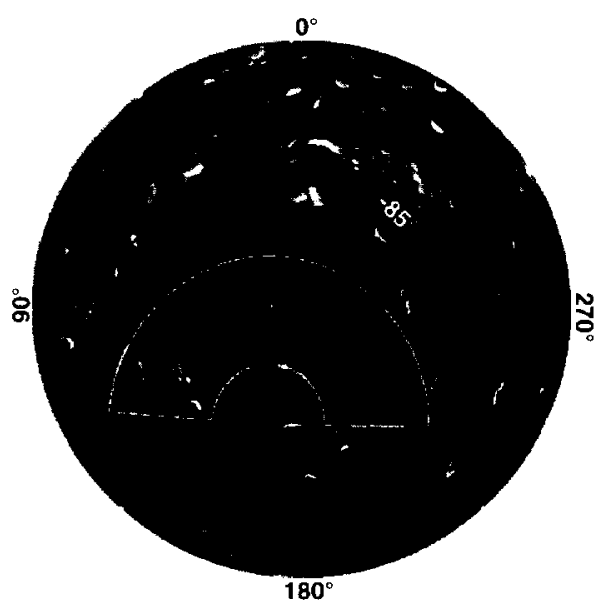

Fig. 4. Clementine mosaic of the south pole region of the moon showing area sampled on orbit 234. The white outline indicates the nominal area at the time of peak RCP response on orbit 234 , as shown in Fig. 3. The limits of this area are defined by contours of constant Doppler shift of the received signal and the RF terminator on an idealized spherical moon. The spread of Doppler shift was chosen to maximize the fraction of permanently shadowed ground in the area sampled. On the actual moon, the true boundaries are irregular. owing to topography, and the fraction of the sampled area occupied by permanently shadowed ground probably is higher than in the idealized case. reversal will be muted hy reflections from the larger surromding lonar surface area. Rocky lunar regolith may cover and be mixed with any ice deposits, further reducing the peak amplitude by increasing loss in the medium. Using the abserved orbit 234 maximum, and median RCYP/LCP' ratios (Fig. 3 and Table 1), and merhonk used to estimate the extent of the Mercury polat deposits (23), we estimate the pure ice equivalent area of putative south pole ice deposits to be un the order of 0.2 to $0.3 \%$ of the ohserved region, or approximately $90 \mathrm{n}$ $135 \mathrm{~km}^{2}$. This area is consistent with small patches of high $(\geq 1)$ RC.T/LC.P surface (hserved from Arecibo (25). The estimate may be a kower limit, als the viewing geometry does not allow ohervation of the deepest parts of the shadewed terrain. The hroad orhit 234 RC:P/LC:I peak and the low value of RC.P/LC.P $(<1)$ are consistent with rigorous theoretical calculations of (CBC)E for measurements made at grazing incidence angles, issuming wavelength scale scatterers imbedded in a lossy medium $(7-12)$. The ohserved orhit 234 RCP peak width and magnirute is predicted hy C.BOE theory if the scittering centers are nonspherical (11) and cover only a fraction of the sampled areal. In this case the predicted LCP peak amplitude would be significantly smaller and its width much larger than the ohserved orbit 234 RC P' peak (12), and is not ohservable in the Clementine data owing to the inherent fluctuation of the much larger LCP background. This does not preclude the existence of a number of small scattering areas with $R C . P / L(C . P \gg 1$ and corresponding sharper LC Cl peaks that cannot he resolved in the datia. These assumptioms are geologically realistic for patchy, dirty ice. Other sattering mechanisms (roughness, double hounce) might explain the oherved south pole RC:P enhancement. However, the Clementine histatic radir datal only stow this entrancement around $\beta=0$ in an area at the lunar south pole containing at least $6361 \mathrm{~km}^{2}$ of permanently shadowed

Table 1. Circular polarization ratio (RCP $/ L C P$ ) median value with $95 \%$ confidence interval for data sorted as a function of incidence angle, not as a function of $\beta$. All frequency bins representing $82^{\circ}$ to $90^{\circ}$ angle of incidence are included and presented as a median value. Because the orbit 234 RCP/LCP ratio is statistically greater than the other orbits, it is untikely that this larger ratio would be found for other orbits when sorted on the basis of high angle of incidence.

\begin{tabular}{ll}
\hline Orbit & RCP/LCP median value (dB) \\
\hline 234 & $0.449+0.019(3.476 \pm 0.178)$ \\
235 & $0.325+0.011(4.885+0.151)$ \\
301 & $0.354 \pm 0.014(4.512+0.171)$ \\
302 & $0.318+0.012(-4.978+0.166)$ \\
\hline
\end{tabular}


terrain. Clementine histatic radar datat taken from other, intermittently sunlit areas with similar geometry, and suhjected to the same datit reduction process, show no evidence of sech an enhancement. This leads to the conclesion that the scattering mechanism responsible for the orbit 234 enhamcement is associted with the permatnently shadewed terrain, which is suggesstive of a muted $(B B C)$ originatting from small patches of ice (and/or other frozen volatiless covered and mixed with recky material

\section{REFERENCES AND NOTES}

1. K. Wetson. B. C. Murray, If. Brown, J. Geophys. Res. 66, 3033(1961)

2. J. R. Armold ibid 84, $5659(1979)$

3. D. A. Paige, S. E. Wood, A. R. Vacavada, Science 258, 643 (19902)

4. A. P. Irkersoll, T. Svitek. B. C. Murray. kians 100,40 $1992\}$

6. J. F. Salvait and F. Fanale, ibrd. 111, 441 (1994)

6. S. J. Ostro and E. M. Shoerraker, wid 85,335 $1930 \%$

7 K. J. Poters Phys Rev. 46, 801 (1992)

8. S. Etemat of at, Phys. Rev Let 59, 1420, (1987).

9. M. 1. Mishohenko, Astrophys. Spatce Sor 194.327 (1992!.

10. F. F. Corodrichev, S. L. Dudarev, D. B. Rogozkm Fhys. Lett. A 144, $48(1990)$.

11. M. I. Mishchenko, J. Opt. Soc. Am. A 9, 978(1992)

12 Furth Moon Planets $58,127\{1962\}$

13. B. Hapke, lcanus 88, $407(1990)$.

14. and [3. Btowitt, Neature 352,4619991)

15. D B Compoll ot al loares 34.254/1978t.

16. R. M. Goldsten and R. P. Green, Scence 207, 179 (1980\}

17. S. Ostro, in Satelltes of Jupiter, D. Morrison, Ed Univ. of Arizona Press, Tucsson. 19821.

18. D.O. Muhteman. B. J. Butler, A. W. Grossman, M. A. Slade, Science 253, 1508 (1991).

19. E. J. Rignot. S. J. Ostro. J. J van Zyl. K. C. Jerek. ibid 261. $1710(1993)$

20. E. J. Rignot, J. Geonths. Res. 100.9389 (1996)

21. J. K. Harmon et.al. Nature 369. $213\{1994\}$

22. M. A. Slade. B. J. Buther D. O. Muhleman, Solonee 258. $635 \div 1992$

23. B. J. Butler, D. O. Muhleman. M. A. Skacte, J. Geophys. ties. 98, $15003(1993)$

24. V. Eschleman. Sctence 234,587(1986)

25. N. J. S. Stacy, thesis, Cornell Unversity (1993).

26. S. Nozette el at. Scremoe 266, 1835) (1944)

27. E. M. Shoemaker, M. S. Bobinson, E. M. Eliason, ibrt. 1851.

28. P. D. Spudis et al, Limar Ptanet. Sci XXVI, 1339 (1995)

29. P. D Soudis et al Science 266. $1848(1994)$

30. P. D. Spudis, in The Geokgy of Multi-ring impact Basins iCambridge Univ. Press, Cambridge, 1993)

31. M. T. Zuber ot at Science 266, 1839 (1994).

32. R. A. Simpson, IEEE Irans GRS-31, 465 (1993).

33. Analvsis was conducted using fast Fourier transform FFT' techniczues The target area is isolated by Dopoler shitt, which relates bands of constant trequency to a set of huar around locatons ithe $\beta-0$ track. The ground points were close? enough in distance to include all of the bands of constant frequency in the siflected area. Repeat responses were fil tored cust. The analyses to extract radar scattering information from local reglons on the surlace were performed by sorting the Doppler data accordmg to the parameter of intoress. Typical freaufency domain transfom paramoters used were 1 to 4 seconds of noncoherent atueraging. 4096 to $16,38 \%$ points per FF, a von Hann time data wirdow withoul zero. padding. and magnitude-only ipower dala stored in double precision output.

34. J. V. Eving and 1. Hagtors. Eds. Rudat Astronomy
MoGraw-Hill New York, 1968 .

35. The effective system noise temperature baseline was eslmated by comparing measured noise from the zonth (20 K), moon center $(235 \mathrm{~K})$, and lunar poles (90 K). Measurements of ambient temperature mi crowave resistors added further corroborating mea surements to the set of calibration data. The noise baseline when considered against the recorded atton wat or values, was used to calibrate the amplitude of the data files into units of signal-to-noise ratio (SNR). Calibration to flatten the frequency response variation arising from receiver filters was performed usimy noise only segments of data. The calibrations included: linear gain change, nonlinear gain change, recording channel frequency response. system noise temperature changes, erroneous data bridgeover. transmitter Irequency variation, transmitter nower variation, and antenna pointing. A small amount of corrupled data is inevitably recorded. The short periods of corrupted data were flagged and suppressed during subsequent analyses. Space cralt attitude files were corrected for known timebase and pointing systematic errors. One-way light time propagation delay effects were included. Sys termatic errors that simultaneously affect the absolute baseline or bias measurement of each polarization chamel were ostimatad to be less than $+2 \mathrm{~dB}$ Sys tematic errors in the ratio measurements are esti mated at $+0.25 \mathrm{~dB}$. The systematic errors common to both channels are suppressed when considering the ratio. Thermal noise variation is negligible be cause several hundred to several thousand frequen$c y$ bins were averaged together, each having a ther mal SNR groater than 10 . Target speckle variation is believed to be the dominanl stochastic error source. The mean walue and error bars given in Fig. 3 are donved by reducing the data sat standard deviation by the square root of the number of noncoherently averaged sumples represented by each point on the plot. The use of noncoherently averaged FFTs and numerous frequency bins reduced this varlation to about +0.1-0.2 dB standerd deviation. Median filter ing was used. Due to the time sampling, regional averaging, and syacecraft system characleristiss the resolution in $\beta$ is $+02^{\prime \prime}$. Due to Doppler bin migration ( \pm 1 bin', ptrase noise of the spacecrift oscillator ( \pm 2 bins), and FFT windowing effects ( $:-2$ bins), the Doppler band regions have an estimatid rms resolution uncertainty of about $\pm 25 \mathrm{~km}$ at -81 latitude, for the 16,384 point FFT data files.

36. L. Tsang, J. A. Kong, R. T. Shin. Theory of Micriwave fiemote Sensing (Wiley-Interscience, Nen York, 1985)

37. A standard analysis of variance (ANOVA) for unbilanced design was pertormed on the data from each orbit ANOVA tests the null hypothesis that the means are the sames and only appear different in measurement becausie of random fluctuations in $t: \epsilon$ data. This analysis tests the statistical significance i the differences among the means. The data reprysented target return bins corresponding to angles of incidence greater than $82^{\prime \prime}$

38. The authors thank the NASA/JPL and Deep Spare Network individuals who supported and helped carry out these observations, in particular S. Asmar; the Clementine lunar operations team led by $\mathrm{T}$. $\mathrm{S}$ : rensen, assisted by $R$ Campion and $T$. Tran; $P$ Rustan of the U.S. Air Force, the Clementine 1 program manager, D. Duston of BMDO, and L. Wood of LLNL: and R. Simpson and $G$. Pettengill for revien and insight. Funding for this work was provided by the Department of Defense, including the Ballistic Missile Defense Organization, the Naval Research Laboratory, the U.S. Air Force Phillips Laboratony Space Experiments Directorate, the Department if Energy, Lawrence Livermore National Laboratory, and NASA. This paper is Lunar and Planetary Institute contribution 899

3 June 1996; accepted 22. October 1996 
